\title{
MEMORIA Y ARQUEOLOGÍA: \\ EL CULTO A LOS MUERTOS ENTRE LA ANTIGÜEDAD \\ TARDÍA Y EL MUNDO MEDIEVAL EN CATALUNYA
}

\author{
Gisela Ripoll \\ Universitat de Barcelona \\ giselaripoll@ub.edu \\ Núria Molist \\ Museu d'Arqueologia de Catalunya \\ nmolist@gencat.cat
}

Nota preliminar: Este trabajo se enmarca dentro de las actividades del ERAAUB / Equip de Recerca Arqueològica i Arqueomètrica, Universitat de Barcelona (Grup de Recerca Consolidat SGR2009-0II73, <www.eraaub.com>), gracias al Comissionat per a Universitats i Recerca del DIUE de la Generalitat de Catalunya, y también en los proyectos de investigación HAR2009-I3104/Hist. y HAR2OI235177/Hist. (<www.carehispania.com>)

La muerte y los muertos son la expresión identitaria más certera de una comunidad, y constituyen factores determinantes en el conocimiento histórico de una sociedad en su sentido más amplio. La arqueología funeraria tiene por objetivo aproximarse al conocimiento de las sociedades del pasado, de los vivos que crearon, adoptaron y transformaron la diversidad de los ritos funerarios. Por tanto, el investigador está obligado a interrogar e interpretar las formas de enterramiento y los restos materiales contenidos en las sepulturas. Esta dimensión social, cultural y económica de las prácticas funerarias tomó fuerza a partir de los planteamientos de Lewis R. Binford (1971 y 1983). Con su obra, así como con la de otros defensores de la Nueva Arqueología, se consiguió superar la etapa descriptiva basada en la adscripción tipológica y cronológica de tumbas y necrópolis. Hoy el grado de profundidad analítica derivado de la relectura de fuentes y de las nuevas herramientas metodológicas aplicadas por la arqueología, permite considerar el culto a los muertos como un campo lleno de posibilidades para conocer las diferentes facetas del paso de la antigüedad tardía a la Edad Media.

Precisamente el caso del nordeste peninsular, la Catalunya actual, es un ejemplo paradigmático de este periodo. Treinta años atrás, Manuel Riu (1982) plan- 
teaba toda una serie de cuestiones sobre las costumbres funerarias, poniendo en relación arqueología, textos, epigrafía, etc. e interrogándose por primera vez sobre la liturgia funeraria y la importancia del lugar de entierro con el fin de reconstruir el imaginario social. Sin embargo, su principal inquietud fue la de establecer una tipología, problema por otra parte recurrente en la literatura arqueológica a partir de aquel momento. El trabajo de M. Riu y el anejo de Acta Mediavalia (1982) que editó, son $-\mathrm{y}$ siguen siendo- referentes para los investigadores interesados en el mundo funerario. En la misma publicación se puso de manifiesto otra de las preocupaciones del momento: la necesidad de sistematizar la recogida de datos fruto de las intervenciones arqueológicas, lo que conocemos como fichas de registro, justo en el momento previo a la incorporación de la informática en el tratamiento de los datos. La monumental Catalunya Romànica, que se fue confeccionando y publicando entre los ańos I980 y finales de los años I990 —XXVII volúmenes en total—, y cuyo objetivo era recopilar la totalidad la arquitectura románica del país, tuvo el acierto de integrar todos los datos conocidos procedentes del mundo funerario de los siglos XI al XIII, desde las necrópolis parroquiales a las tumbas aisladas. Algo inesperado en unos volúmenes donde la historia, los textos, el arte y la arquitectura son los protagonistas de la reconstrucción "enciclopédica" del periodo. No sorprende, sino al contrario, que en el volumen dedicado a la antigüedad tardía, Del romà al romànic, dirigido por P. de Palol y A. Pladevall (1999), se consagren algunos capítulos al análisis global de las necrópolis, a los depósitos funerarios y a los materiales relacionados con la indumentaria de los difuntos; la necrópolis de La Tabacalera o del Francolí de Tarragona, descubierta en la década de 1920 y excavada por Mossén Serra Vilaró, representa un punto de inflexión en la investigación de la arqueología funeraria — llamémosle "paleocristiana"- y el culto martirial.

En esta etapa de primeros intentos de sistematización asistimos a la incorporación paulatina de los análisis antropológicos de los individuos inhumados. La primera síntesis de la población medieval catalana realizada en base a los datos proporcionados por las excavaciones arqueológicas (una treintena de necrópolis datadas entre los siglos IX i XI) vio la luz en 1990 de la mano de E. Vives, aportando resultados antropométricos y demográficos. En la publicación se enfatizaba la pronunciada dolicocefalia, la altura relativamente importante (casi $166 \mathrm{~cm}$. los hombres, $154 \mathrm{~cm}$. las mujeres), el elevado grado de mortalidad en mujeres que no llegaban a la edad madura y también los altísimos índices de mortalidad infantil. Y es sintomático que, transcurridos más de veinte años, nadie haya puesto al día esos datos, aunque las excavaciones arqueológicas y los estudios antropológicos han crecido exponencialmente. La lectura no es negativa, al contrario, es positiva porque las bases están bien establecidas. No obstante, son necesarias ciertas matizaciones. 
La arqueología de las tres últimas décadas se caracteriza por la profesionalización, el radical aumento de las intervenciones debido a la presión urbanística, la voluntad (muchas veces más aparente que efectiva) de proteger legalmente el patrimonio, la incorporación de la informática en la gestión de los datos y la realización de análisis, en especial de radiocarbono, con el fin de obtener dataciones absolutas. Respecto a este último punto, los análisis han aumentado las posibilidades de obtención de datos más allá de la simple observación visual. El coste económico sigue siendo un impedimento en su aplicación generalizada. El estudio del ADN y de diferentes componentes químicos como el estroncio presente en los restos humanos, por poner un ejemplo, abre una importante vía hacia el conocimiento de la población y el individuo (características físicas, enfermedades, hábitat, desplazamientos...).

Los aspectos mencionados son muy positivos, pero son también armas de doble filo que han implicado la dispersión y fraccionamiento de la difusión de los datos y, sobre todo, un constante cuestionamiento de la metodología a utilizar frente a la necesidad de aglutinar equipos interdisciplinares. El modelo que se ha impuesto es a día de hoy obsoleto, porque prevalece la cantidad sobre la calidad, y el método sobre la reflexión histórica. Las numerosas publicaciones de jornadas arqueológicas como las de las comarcas de Girona (once ediciones entre 1992 y 20I2), o las de las reuniones de la Associació Catalana per a la Recerca en Arqueologia Medieval i Moderna (a finales de 201 se han publicado las actas del cuarto congreso) no dejan de ser una gran fuente de información para trabajar sobre el culto a los muertos, aunque eso sí, siempre desde la perspectiva de la recogida y descripción de datos resultado de las excavaciones, en su mayoría preventivas. Cabe resaltar el esfuerzo hecho por el Servei d'Arqueologia (Departament de Cultura, Generalitat de Catalunya) por digitalizar y facilitar el libre acceso a las memorias arqueológicas de las excavaciones, así como a los inventarios de la carta arqueológica.

Este acopio de intervenciones y datos nos llevó a convocar una sesión de trabajo en 2009 (Arqueologia funerària al nord-est peninsular entre els segles VI $i$ XII), tras una larga reflexión sobre cuáles eran los principales desafíos que planteaba la arqueología funeraria a inicios del siglo xxi. Nuestra intención era la de dar a conocer, a través de una publicación editada a fines de 20I2, cerca de cincuenta necrópolis, muchas de las cuales habían quedado "enterradas" — nunca mejor dicho- en los fondos de laboratorios, museos y despachos. Ha llegado, pues, el momento de plantear cual es la vía para ordenar, gestionar y explotar científicamente todo ese enorme volumen de datos arqueológicos, y muchos más que aún están inéditos o publicados de forma deficitaria.

Un buen ejemplo de cómo se puede llegar a trabajar hoy en día es el proyecto de intervención de la tumba de Pere II del monasterio de Santes Creus. Se trata 
aquí de un modelo de trabajo interdisciplinar, iniciado en el año 20ıo, un caso singular y a la vez único: un estudio concebido como proyecto de investigación (dirigido por el Museu de Història de Catalunya) y dotado de un equipo en que han participado historiadores, arqueólogos, antropólogos, médicos, biólogos, restauradores, así como otros especialistas, y cuyos resultados han puesto de relieve el potencial analítico practicable en una única sepultura; real, sí, pero en definitiva un ejemplo de arqueología funeraria. La proyección mediática conseguida, e incluso la publicidad dada a algunos de los hallazgos, como la reconstrucción facial del rey, el uso de tinte para colorear el cabello, el relleno aromatizado del cojín, etc., ha permitido cumplir con una de las obligaciones esenciales de los científicos, y que olvidamos demasiadas veces, que es la de devolver a la sociedad aquello que le pertenece. No es lo mismo una tumba real con el cuerpo momificado que las necrópolis dispersas en el territorio, y es evidente que no es posible hacer con todas y cada una de las sepulturas y cuerpos lo que se ha hecho con la de Pere el Gran. Nuestro deber es generar conocimiento histórico, y tendremos que forzar nuestra imaginación y nuestras capacidades para conseguirlo. Es decir, no sirven de nada los datos arqueológicos si no están ordenados convenientemente y si no son cuestionados correctamente. Además de los resultados arqueológicos, es ineludible conocer los textos - fuentes escritas y epigrafía- y los programas iconográficos, para rehacer lo que significó el culto a los muertos y su desarrollo a lo largo del tiempo. El trabajo interdisciplinar es imprescindible. Hay que superar el estadio de descripción cronotipológica y el estudio antropológico de los individuos de cada yacimiento para definir los procesos relacionados con el hecho de morir y enterrar a los difuntos —el culto de los vivos a la muerte- y, por extensión, potenciar el estudio de la sociedad que los generó. Para ello es necesario buscar nuevos caminos y sinergias entre todos los agentes implicados: instituciones administrativas, culturales, científicas y académicas. Sólo así podremos llegar al individuo y a la sociedad, a la memoria individual y a la colectiva.

\section{REFERENCIAS}

Se referencían las citas indicadas en el texto, además de algunos títulos que se consideran de interés.

Ariès, PH., El hombre ante la muerte, Madrid, 1983.

Binford, L. R., "Mortuary Practices: Their Study and their Potential", American Archaeology 25 (197I), pp. 6-29; traducción castellana en: "Las prácticas funerarias: su estudio y su potencial”, Pyrenae, 42.I, 20II, pp. II-47. 
Binford, L. R., In Pursuit of the Past. Decoding the Archaeological Record, Londres, I983.

Duval, Y., Auprès des saints corps et âme. L'inhumation "ad sanctos" dans la chrétienté d'Orient et d'Occident du III à vII Siècles, París, I988.

Crubézy, E., Masset, C., Lorans, E., Perrin, E., y Tranot, L., Archéologie funéraire, París, 2000.

Molist, N., y Ripoll, G. (eds.), Arqueologia funerària al nord-est peninsular (segles VI-XII), Monografies d'Olèrdola 3.I y 3.2, Museu d'Arqueologia de Catalunya, Barcelona, 20I2.

Palol, P., y Pladevall, A. (dir.), Del romà al romànic. Història, art i cultura de la Tarraconense mediterrània entre els segles IX $i$ X, Catalunya Romànica, Enciclopèdia Catalana y Ed. 62, Barcelona, I999.

Paxton, F. S., Christianizing Death. The Creation of a Ritual Process in Early Medieval Europe, Ithaca-Londres, I990.

Ripoll, G., y Molist, N., "L'arqueologia funerària a Catalunya: de l'antiguitat tardana al món medieval", en N. Molist y G. Ripoll (eds.), Arqueologia funerària al nord-est peninsular (segles VI-XII), Monografies d'Olèrdola 3.I y 3.2, Museu d'Arqueologia de Catalunya, Barcelona, 2012.

Riu i Riu, M., “Alguns costums funeraris de l'Edat Mitjana a Catalunya”, en M. Riu (ed.), Necròpolis i sepultures medievals de Catalunya, Acta Mediavalia, Annex I (1982), pp. 29-57 (= Discurs de Recepció, Reial Acadèmia de Bones Lletres de Barcelona, Barcelona, I983).

Riu i Riu, M. (ed.), Necròpolis i sepultures medievals de Catalunya, Acta Medicvalia, Annex I (1982).

SICARD, D., La liturgie de la mort dans l'Eglise latine des origines à la réforme carolingienne, Münster Westfalen, I978.

Treffort, C., L'Église carolingienne et la mort. Christianisme, rites funéraires et pratiques commémoratives, Lyon, 1996.

VIVes, E., La població catalana medieval. Origen i evolució, Vic, 1990. 